185

\section{Q-CARE PROFILES: DEVELOPMENT OF A NEW INSTRUMENT TO STIMULATE COMMUNICATION WITH ADOLESCENTS WITH CHRONIC DISORDERS DURING CONSULTATIONS}

A. van Staa ${ }^{1,2}$ S. Jedeloo ${ }^{1}$, On Your Own Feet

${ }^{1}$ Expertise Centre Transitions of Care, Rotterdam University, ${ }^{2}$ Institute Health Policy \& Management, Erasmus University Rotterdam, Rotterdam, The Netherlands

Background: A previous Q-methodological study revealed four distinct preference profiles for health care delivery and self-management: 'Conscious \& Compliant'; 'Backseat Patient'; 'Self-confident \& Autonomous'; and 'Worried \& Insecure'.

\section{Aim:}

1) To examine the prevalence of $Q$-care profiles (QCP);

2) To explore the associations with adolescent characteristics and

3) Develop an attractive tool for communication during consultations.

Mehods: Web-survey among all chronic patients (12-19 yrs) of a paediatric hospital and their parents. Adolescents' fit to the Abbreviated QCP descriptions was scored on a five-point Likert-scale.

Results: 990 adolescents and 778 parents responded. Adolescents recognize themselves twice as often in the 'Conscious \& Compliant' profile than in the other profiles. Fit to any of the profiles is associated with age, gender, quality of life, impact of disease, self-efficacy, independent behaviour and readiness for transition. While the 'Backseat Patient' and the 'Worried \& Insecure' type feel less selfefficacious, the 'Self-confident \& Autonomous' type is at risk for non-adherence. Parents \& children's assessments correspond fairly well, but there are significant differences.

Conclusions: The Q-care profiles are recognizable to adolescents and parents, and they discriminate fairly well. The QCP seem potentially suitable to stimulate communication with adolescents. A practical manual for use of QCP during consultations was developed, including tips for interventions to be used by healthcare providers to address typical problems associated with each profile. Further research into the applicability of this new tool and the possibility to use the Q-care profiles as a screening instrument for self-management failure is now underway.

\section{6}

\section{CHALLENGES IN CHILD SEXUAL ABUSE HUNGARY}

\author{
R. Csorba, R. Lampe, R. Poka \\ Medical University of Debrecen, Debrecen, \\ Hungary
}

Objective: Between 1986 and 2005, 266 girls under the age of 18 had been exposed to sexual abuse. We summarize the characteristics of child sexual abuse cases and explore common features.

Methods: We prospectively collected data according to characteristics of all cases. Legal procedures were also evaluated. We describe the medical and legal approaches to handling child neglect.

Results: Seventy-eight percent of the victims were students, and $45 \%$ of them were between 11 and 14 years of age. Perpetrator was familiar to the victim in $67 \%$ of the cases, and a stranger in $33 \%$. Seventy-five (28\%) perpetrators were members of the victims' families. In $14 \%$ of cases, the perpetrator was the victim's father and in $9 \%$, her stepfather. The abuse had occurred on multiple occasions in $29 \%$. The occurrence rate of assault was highest in the summer season (54\%). Vaginal penetration was the type of abuse in $63 \%$, and sexual perversion in $37 \%$. Eighty-five victims were physically injured, and in 40 cases the presence of sperm was confirmed. Two pregnancy occurred. 167 cases were reported to the police; 68 of the perpetrators were sentenced as a result of legal proceedings.

Conclusion: Majority of sexual abuse takes place within the family and is revealed after multiple episodes. The underestimated prevalence of sexual assault is the consequence of the lack of cooperation between the emergency services and the Hungarian criminal law. Prevention requires vigilance in out-of-school times, child education, early involvement of healthcare professionals, and adjustment of the administration of justice. 